\section{A NATURALIZAÇÃO DO PRECONCEITO NA FORMAÇÃO DA IDENTIDADE DO AFRO-DESCENDENTE}

\author{
Ricardo Franklin Ferreira* \\ Amilton Carlos Camargo**
}

\begin{abstract}
Resumo: O presente trabalho, partindo de duas situaçōes paradigmáticas do diaa-dia, aponta algumas especificidades de como o preconceito e a discriminação racial são veiculados no Brasil; de que maneira tais processos são alimentados e mantidos; pontua como esse contexto cria dificuldades na construção de uma identidade referenciada em valores positivos e a decorrente dificuldade no exercício da cidadania; e, finalmente, aponta um processo que possibilita a construção de uma identidade afro-centrada. É dada ênfase à situação escolar como um 'lugar' de retroalimentação desses processos.
\end{abstract}

O Brasil, como outros países da América, desenvolveu-se como nação a partir da vinda dos europeus, do genocídio das populaçóes indo-americanas e de um sistema econômico baseado na mão de obra escrava de populações africanas aprisionadas ${ }^{1}$. Tais condições históricas favoreceram a presença dos valores africanos nas manifestaçóes culturais brasileiras, que permaneceram preservados ao longo da sucessão de geraçôes, mostrando-se tacitamente ativos e constituintes do processo de formação da cidadania. (Ribeiro, 1996)

Entretanto, a pessoa negra traz do passado a negação da tradição africana, a condição de escravo, o estigma de ser um objeto de uso como instrumento de trabalho e tem de lidar, no presente, com a constante discriminação racial e, mesmo sob tais circunstâncias, tem a tarefa de construir um futuro promissor.

O Brasil, em relação às outras nações americanas, foi o país a escravizar o maior número de africanos e o último do mundo cristão a abolir a escravidão. Apesar destes dados, entre 1900 e 1950, o Brasil cultivou, com sucesso, a imagem
PALAVRAS-CHAVE: brasileiro afrodescendente; preconceito racial; discriminação; identidade.

*Doutor em Psicologia (USP). Professor e vice-coordenador do Programa de Pós-Graduação em Psicologia da Universidade São Marcos.

**Graduando em Psicologia da Universidade São Marcos.

${ }^{1}$ Pinsky (2000) relata que dos 8.330.000 de africanos apresados, cerca de $40 \%$, morriam nos seis primeiros meses após sua captura, ainda na África, enquanto esperavam serem transportados para o Brasil, $12 \%$ morriam durante o mês em que ficavam nos portos aguardando o embarque, $9 \%$ morriam durante a viagem e cerca de 4.400 .000 chegaram aos portos brasileiros, com 2 milhões sobrevivendo mais de cinco anos. 
de ser a primeira 'democracia racial' do mundo, onde a convivência entre brancos e negros era descrita como harmoniosa e igualitária.

Tal concepção, tornada discurso oficial, é na verdade um mito. Este, hoje questionado, mas que ainda encobre perversamente a discriminação negativa e o preconceito contra essa população, tornando muito difícil o combate efetivo da injustiça para com indivíduos e grupos etno-raciais diversos do branco-europeu.

\section{Cenas do cotidiano}

No cotidiano do afro-descendente a discriminação é mantida, nas relações pessoais, por processos sutis. São processos muitas vezes silenciosos, encobertos por 'frases educadas' e eufemismos. Vejamos um exemplo: uma pesquisadora negra, em seu trabalho de mestrado (CAVALLEIRO, 1998), cita literalmente a fala de uma professora de pré-escola, localizada na cidade de São Paulo, que se considera sem preconceito racial, acredita que algumas pessoas ainda o mantêm e sugere uma 'saída' para o problema da discriminação:

... porque o preconceito de raça, se você pensar bem, geralmente é em matéria de cheiro. Uma pessoa que é negra, a pele, a melanina faz com que o cheiro fique mais forte. Hoje em dia, esse preconceito de cheiro já melhorou muito com os produtos modernos das nossas indústrias - os desodorantes, as 'minâncoras' da vida (pomadas). Esses tipos de antitranspirantes fazem com que não exista o cheiro. Não havendo o cheiro, não existe o porquê de o branco não conversar com o preto e vice-versa. Tem gente que melhorou e muito. Por que, o que é o preconceito? Preconceito é por causa da sujeira. O cheiro é ruim e gera sujeira. É exatamente por causa do cheiro. É o cheiro que fez com que aparecesse esse preconceito (...).

Este exemplo reproduz 'máximas' praticadas diariamente no Brasil, ficando evidente que o preconceito contido em tais afirmações já não é percebido por quem as profere, considerando que a entrevistadora que colheu tais depoimentos é uma mulher negra, de maneira tal que sugere estar incorporada nas construçôes pessoais dos indivíduos uma concepção de menor valia do negro em comparação ao branco. 
Isso nos remete a uma idéia de desumanização do negro. $\mathrm{O}$ afro-descendente deixa de existir como uma totalidade, sendo representado e reduzido, neste caso, a um 'problema de cheiro', descrito como natural, forte, desagradável e associado à sujeira. Assim, vemos 'explicado' todo um complexo processo historicamente construído que, por meio de mecanismos sutis e perversos, remetem o negro ao desprestígio e à exclusão social.

Queremos ressaltar que tal frase foi proferida por uma professora, que contribui diariamente para o processo de socialização de várias crianças na préescola. Pode-se perceber que seu argumento aponta uma 'possível solução' para o problema do preconceito: como a indústria de cosméticos está evoluída, existe a tendência de acabar com o cheiro desagradável do negro; eliminado o cheiro, o preconceito acaba.

Verifiquemos mais um exemplo, de outra professora, querendo mostrar à pesquisadora (CAVAlleiro, 1998) como lida com as histórias infantis, e quanto suas relações pessoais com crianças negras estão desprovidas de preconceito:

Nas próprias histórias infantis, existe aquela história da madrasta, da bruxa. Em relação a uma coisa má e a uma coisa boa. Então, a gente pode aproveitar a raça nesse sentido. Porque, às vezes, uma pessoa, por exemplo, é preta e tem a alma branca. As pessoas também são diferentes, podem ser negras (ou) da raça branca, mas todas são iguais. São feitas de carne e osso. Porque, às vezes, uma pessoa, por exemplo, é preta e tem a alma branca. E a branca pode ter a alma preta. (p. 129)

Tal fala mostra uma outra maneira de o preconceito ser veiculado. Trata-se de uma frase que pretende 'mostrar' como a professora, a partir das histórias infantis, 'aproveita' para lidar com a questão do preconceito com as crianças na sala de aula. Pode-se perceber que a cor negra está associada ao mal, e a cor branca, ao bem.

Se considerarmos, pelas relaçôes interpessoais - caso da escola - as práticas sociais diárias um fator de fundamental importância para a construção de identidades, vislumbraremos a possibilidade de os brancos terem seus constructos de identificação referenciados em uma 'superioridade' sustentada por raízes européias, e o negro, uma 'inferioridade' construída pela desvalorização de suas características pessoais e matrizes africanas. 
Para falarmos do preconceito, torna-se importante compreendermos certas especificidades brasileiras. Uma delas é que a cor e as características físicas acabam operando como referências que contêm duas faces associadas de forma inseparável - a raça e a condição social, o que leva o afro-descendente a julgar-se inferior, não somente quanto ao aspecto racial, mas também em relação aos aspectos socioeconômicos. Isto cria condições para uma concentração racial de renda, de prestígio social e de poder pelo grupo dominante (SouZA, 1991). Entretanto, existe a negação do preconceito racial por este mesmo grupo, atitude que tende a manter a idéia de serem as mazelas inerentes ao destino humano do negro. Mecanismos decorrentes dessa negação podem ser historicamente observados - desde o extermínio dos afro-descendentes, como na época do Brasil Colônia, até o mecanismo de 'branqueamento'. Este mecanismo implica assumirem-se as características do brancoeuropeu como representativas de sua superioridade étnica. Em contrapartida, o negro é visto como um tipo étnica e culturalmente inferior. Entre essa dicotomia, estabeleceu-se uma escala de valores, um 'gradiente étnico', de tal maneira que a pessoa com características mais próximas do tipo branco tende a ser mais valorizada, enquanto aquela, cujas características a aproximam do tipo negro, tende a ser desvalorizada e socialmente repelida. Assim, no Brasil, criou-se historicamente a crença de ser a miscigenação um processo pelo qual o afro-descendente tornarse-ia mais respeitado e teria mais possibilidades de ascender na escala social, além de servir de argumento para afirmar quanto o brasileiro 'aceita' a convivência de raças, isto é, que não há preconceito no Brasil.

Esse processo torna-se dramático, pois o preconceito é veiculado de uma forma geralmente encoberta, alimentando o mito brasileiro de estarmos vivendo num paraíso de coexistência e de aceitação das singularidades, visão que conserva o problema, que deixa de ser enfrentado por criar-se a idéia de ele não existir.

Parece ser politicamente correto tratar o afro-descendente como 'moreno'. Este eufemismo, fortemente enraizado na cultura brasileira, é um recurso simbólico de fuga de uma realidade em que a discriminação impera. Assim, os aspectos etno-raciais são escamoteados pela maioria das pessoas que procuram elementos de identificação em símbolos do grupo social e economicamente dominante.

Outro problema está ligado à percepção das características etno-raciais. É comum a autopercepção diferir da percepção do outro no que se refere às carac- 
terísticas físicas e étnicas. Freqüentemente, indivíduos que se consideram brancos são vistos como negros por outros. D’Adesky (1996) aponta como o modo de vida e o status acabam sendo fatores determinantes na classificação da cor. É muito comum a pessoa com características negróides leves e posição social elevada - caso do mestiço - ser considerada branca. Pelas especificidades socioeconômicas adversas, a pessoa com características físicas semelhantes pode ser considerada negra. Há uma ausência de unanimidade, o que vem a criar dificuldades adicionais para a construção da identidade do afrodescendente. No caso do mestiço, este processo torna-se mais intenso, pois, como nos aponta Reis (1997), ele está submetido a uma ambigüidade de ser um e outro, um branco-não-branco e um negro-não-negro.

É importante entendermos o processo de construção do preconceito etno-racial e sua expressão comportamental, a discriminação. O preconceito é um julgamento de valor, construído culturalmente e destituído de base objetiva, pertencendo à classe de mitos desenvolvidos por meio da socialização.

No Brasil, o preconceito racial foi construído a partir da interação entre dois grupos: uma classe política e economicamente dominante, com uma concepção de mundo considerada superior, que passou a dominar um outro grupo pela estrutura econômica baseada na escravidão; o grupo dos negros, que passou a ser considerado inferior, crença que levou a justificar a dominação sobre ele. À medida que o grupo dominado passa a compartilhar as mesmas crenças sobre si mesmo e a submeter-se ao controle imposto, o processo se legitima.

Os aspectos étnicos de matrizes africanas têm servido de referência para a avaliação negativa de pessoas. $\mathrm{O}$ processo de construção e manutenção do racismo, considerado aqui como prática discriminatória institucionalizada (PEREIRA, 1996), apresenta as culturas africanas como folclóricas, primitivas e inferiores, se comparadas com a branco-européia. A partir de tal visão, alguns de seus elementos são simplesmente omitidos nos estudos da formação do brasileiro, com exceção dos aspectos ligados à escravidão a que o africano foi submetido.

Assim, a sociedade brasileira criou mecanismos desfavoráveis ao desenvolvimento de identidades articuladas em torno de valores percebidos como positivos, o que evidentemente determina a dificuldade de os afro-descendentes exercerem sua cidadania.

Há, entretanto, como já apontamos, dificuldade em se compreender o preconceito contra a população negra em virtude do mito que o nega, pois 'não 
temos que compreender o que não existe'. Por causa de tal processo, o afrodescendente tem sido induzido a acreditar que, ao perceber-se discriminado, seu sentimento de menos valia decorre de uma fantasia sua ou, o que é pior, da falta de qualidades pessoais.

Sabe-se da discriminação, mas não se fala a respeito dela. Uma pesquisa do Datafolha (Rodrigues, 1995) ressaltou que o preconceito e a discriminação raciais são sistematicamente considerados atributos do 'outro'. Seus resultados apontam que $89 \%$ dos brasileiros afirmam saber que existe preconceito contra os brasileiros negros, mas somente $10 \%$ o admitem. Schwarcz (1998) chegou a resultados mais extremos - $97 \%$ das pessoas afirmaram não terem preconceito e $98 \%$ dos entrevistados diziam conhecer pessoas com preconceito racial. Portanto, tem-se consciência do racismo; no entanto, considera-se como um problema do outro. Assim, no Brasil, 'vive-se' tacitamente o preconceito. Ele não é abertamente afirmado, dificultando a avaliação da inclusão social do afro-descendente e a elaboração de leis que possam favorecer a reversão desse problema. Torna-se difícil, dessa forma, a construção de uma identidade positivamente afirmada por parte da população afro-descendente e, em decorrência, o desenvolvimento de políticas efetivas voltadas para a melhoria de suas condições sociais.

No dia-a-dia das práticas sociais, tanto as pessoas que se consideram parte do 'outro grupo' quanto o próprio afro-descendente, tendem a introjetar valores negativos associados às características etno-raciais negras. Identidades assim constituídas mantêm a incapacidade de desenvolver atitudes afirmativas relacionadas às especificidades raciais. Tais condiçôes constituem terreno fértil para a exclusão social desta grande parcela da população brasileira, condição para um verdadeiro genocídio silencioso, gradual e lento. A experiência da escravidão no Brasil transformou o africano em escravo; o escravo, em negro, e o negro, numa pessoa que tende a desaparecer em nome da constituição de um povo cordial e moreno.

Nessa direção, a idéia do branqueamento como solução foi defendida, no começo do século XX, por vários cientistas e representantes da intelectualidade brasileira. Não podemos nos esquecer de que, na modernidade, os representantes da ciência passaram a ser os legitimadores das 'verdades' estabelecidas na comunidade. Os trabalhos de Schwarcz (1996) e Consorte (1999) analisam com muita propriedade esse período. Muitas justificativas, consideradas científicas, 
legitimavam o eurocentrismo ${ }^{2}$, favorecendo políticas de branqueamento que, para Nascimento, apoiavam-se em duas condiçôes básicas: "a imigração européia em massa, subsidiada pelo Estado, sob legislação que excluía raças não desejáveis, e o cultivo do ideal do embranquecimento" (2000: 117).

Vejamos alguns exemplos. Em 1911, no I Congresso Internacional das Raças, João Batista Lacerda defendia uma tese que previa, na entrada do novo século, a extinção dos mestiços e das pessoas de raça negra (SCHWARCZ, 1998). Nessa mesma direção, o antropólogo Roquete Pinto, em 1927, no Congresso Brasileiro de Eugenia, fazia sua previsão de que, em 2012, a população brasileira seria constituída por $80 \%$ de brancos e $20 \%$ de mestiços, nenhum negro e nenhum índio. O psiquiatra Nina Rodrigues (1988), pioneiro dos estudos científicos da população afro-descendente brasileira, estudou a origem, a cultura, a religião e a influência dos africanos e seus descendentes na Bahia, embora defendesse teses racistas. Adepto do darwinismo racial no começo do século, talvez tenha sido quem proclamou com mais ênfase a inferioridade do negro e a degenerescência do mestiço, considerando a raça negra um dos fatores da nossa inferioridade como povo.

Podemos, então, sintetizar duas condições que legitimavam concepções de menos valia em relação às especificidades etno-raciais dos negros e a decorrente discriminação negativa: a) um processo histórico, apoiado inclusive pela Igreja, que levou à escravidão do africano e o reduziu à condição de mero objeto de uso; b) depois da Abolição, desenvolveram-se concepçôes científicas acerca da inferioridade racial do negro, a ponto de se 'prever' sua extinção na constituição do povo brasileiro.

Num contramovimento, nos anos 30, o mestiço passa a ser louvado como símbolo de nossa identidade. Primeiro a desvalorização e depois a exaltação. Assim, foi sendo gestado um mito que passou a constituir o pensamento brasileiro - o mito da 'democracia racial', formulado de maneira exemplar por Gilberto Freyre.

Temos aqui o terreno para a constituição do racismo silencioso, o peculiar racismo à brasileira - preconceito 'encarnado', constituinte do mundo simbólico dos brasileiros, que alimenta uma visão negativa do afro-descendente, coexistindo, simultaneamente, com um discurso que o nega. São essas as condições em que é gestada a identidade do brasileiro afro-descendente.

\section{A escola e a mídia na manutenção do preconceito}

${ }^{2}$ Cf. Nascimento: "o termo eurocentrismo refere-se a essa imposição sobre os povos dominados de um universalismo hegemônico que define o mundo do ponto de vista do dominador". (2000: 54) 
Neste ponto, cremos ser importante entendermos alguns processos que levam à manutenção do preconceito e da discriminação.

Agências de muita importância no processo de socialização e construção de cidadania, como a escola e a mídia, têm se mostrado fontes de retroalimentação do processo de discriminação racial e de diminuição da importância da cultura africana (RIBEIRO, 1996; GuSMÃo, 1990). Na mídia, os afrodescendentes têm sido representados por meio de imagens estereotipadas, freqüentemente expostos em posiçōes subalternas em relação ao branco, como uma minoria desprezada e sem qualidades estéticas (LimA, 1991). E o que parece mais grave: a escola constituiu-se num espaço onde essas concepções se perpetuam em função das distorções da realidade histórica, omissão de fatos, reprodução de inverdades, sempre para mostrar os povos africanos como 'tribos' estáticas no tempo, alheias ao conhecimento científico e ao progresso humano (NASCIMENTO, 1991). É esclarecedor, nesse sentido, o trabalho de Gusmão (1990), ao esclarecer como a escola propaga aspectos legitimadores da dominação branca e dificulta - quando não impede - o desenvolvimento de uma consciência negra, nega o direito à diferença e aponta como as crianças, tanto brancas quanto negras, têm estes aspectos internalizados e presentes nas interaçôes do dia-a-dia escolar. As falas das professoras apontadas no início do artigo são exemplos claros desse processo.

A escola reproduz naquele microcosmo a mesma estrutura de relação que se dá na sociedade como um todo, isto é, uma relação assimétrica de dominação/subordinação (Miranda, 1989). Assim, em vez de ser um lugar favorável à reversão do problema, estimula os estereótipos referentes aos afro-descendentes e sua submissão aos valores brancos. Cria-se, assim, um processo pedagógico tal que leva o afro-descendente a inibir sua capacidade de advogar os interesses culturais, políticos e econômicos a que tem direito como cidadão. Sua história é interpretada de maneira distorcida. Por exemplo, a escravidão é apontada como uma simples experiência civilizatória. É muito comum que os problemas etno-raciais sejam considerados sob o prisma da 'culpabilidade da vítima', isto é, que as condiçōes sociais e econômicas precárias sejam fruto da inépcia e da falta de capacidade pessoal dos afro-descendentes. Em conseqüência, eles tendem a acreditar na responsabilidade individual pelas situações adversas sofridas, mesmo quando se deram em função de suas características etno-raciais. Alimentam, comumente, a convicção de que a aceitação depende do esforço pessoal, pois o discurso de que no Brasil não há 
preconceito está internalizado.

\section{Dificuldades na construção de uma identidade referenciada em torno de valores positivos e no exercício da cidadania}

Aqui, queremos discutir algumas idéias acerca da identidade e da importância de tal categoria para a compreensão das questóes levantadas.

A existência do homem constitui uma contínua tentativa de 'instalar-se' em seu mundo de uma maneira segura. Para isso, tem de buscar uma ordem significativa entre suas experiências de vida. Quando afirmamos 'buscar uma ordem significativa', estamos querendo sugerir que o indivíduo desenvolve um mundo simbólico que lhe permite organizar suas vivências por meio de 'construções' acerca do real. São referências sobre seu mundo e sobre si mesmo - suas crenças, conceitos, atribuiçôes, padrôes de pensamento. Tal processo ajuda o indivíduo a identificar os objetos em sua especificidade, a construir pautas de ação, levando-o a organizar-se em seus contextos de vida com relativa segurança

As concepções de realidade, construídas nas relações interpessoais, são mediadas pelas crenças, padrões, práticas e normas veiculadas pela sociedade. Esta, por sua vez, é em parte constituída pelo indivíduo dela participante, num processo contínuo e dinâmico de mútua construção, cuja direção não é casual, mas determinada pela somatória das ações políticas de todos os indivíduos que a integram. Assim, em seu conjunto, os indivíduos, em função de suas concepções de realidade, desenvolvem uma sociedade e uma cultura específicas na qual se inserem e, concomitantemente, seu mundo simbólico é também por elas constituído, formando uma estrutura orgânica em que o todo e as partes influenciam-se mutuamente, submetidos a um duplo movimento - o de manter uma certa estabilidade ao longo do tempo e o de prover transformações na própria estrutura.

Sintetizando, as concepçôes de realidade, constituintes do mundo simbólico pessoal, são desenvolvidas socialmente por um processo dialético em que o indivíduo é co-produtor, tanto da sociedade como de si próprio, já ampla e consistentemente discutido, entre outros, por Berger e Luckmann (1972). Assim, a experiência psicológica tem um caráter de construção permanente, em que as 
rências de mundo vão sendo construídas, incluindo aquelas por meio das quais alguém pode reconhecer-se como uma determinada pessoa - sua identidade. São referências, coletivamente compartilhadas, em torno das quais ele organiza a si mesmo e sua relação com o mundo. Dessa forma, a construção da experiência desenvolve-se pelas estruturas de significado, operando sempre como um conjunto organizado, como um sistema de constructos (ALVAREZ, 1992); a identidade é um de seus constructos centrais, determinante para a constituição e manutenção da integridade do próprio sistema pessoal.

Falar de identidade é falar de atores sociais voltados à construção de uma trama dramática. Portanto, não se refere a uma categoria que expressa uma estrutura pessoal fixa; é um constructo que reflete um processo em constante transformação, cujas mudanças vêm sempre associadas a mudanças de referências e a novas construções de realidade por parte dos indivíduos, determinadas por sua participação em certos processos provocadores de impacto existencial.

Alinhados com Ciampa (1987), consideramos a identidade, não como uma simples representação da pessoa, e sim como um processo que, além de representar a pessoa, a engendra. Dessa maneira, a categoria identidade, além de pessoal, deve ser considerada fundamentalmente social e política. É aqui entendida como uma referência em torno da qual o indivíduo se auto-reconhece e se constitui, construída a partir de sua relação com o outro e em constante transformação. Não é uma referência que configura exclusivamente uma unidade, mas simultaneamente unidade e multiplicidade. Portanto, não uma simples representação do indivíduo, mas qualidade submetida a uma tensão ou, usando a concepção de Merleau-Ponty (1971), a 'uma dialética sem síntese'. Talvez fosse mais correto denominá-la dinâmica de identificação, sempre submetida à dinâmica do processo de viver. Esta expressão aproxima-se do que entendemos por identidade - um processo dinâmico em torno do qual o indivíduo se referencia, constrói a si e a seu mundo e desenvolve um sentido de autoria em sua própria vida.

Cremos ser uma categoria efetivamente importante na constituição do indivíduo, determinando sua auto-estima e sua maneira de existir. Nesse sentido, é fundamental, para a compreensão da problemática do afro-descendente, o conhecimento da maneira pela qual ele desenvolve sua identidade, principalmente em contextos sociais adversos, onde é discriminado negativamente.

A compreensão da dinâmica de desenvolvimento da identidade do afro-des- 
cendente torna-se importante para entender a formação da identidade do brasileiro e desenvolver estratégias que favoreçam a construção de identidades positivamente afirmadas, condição para uma vida mais saudável e o efetivo exercício de cidadania.

$\mathrm{Na}$ análise do desenvolvimento da identidade do afro-descendente, utilizaremos o modelo proposto por Ferreira (1999). A partir do processo de desqualificação da pessoa negra, aqui já apontado, é comum os afro-descendentes absorverem as crenças e valores da cultura branca, considerada superior, inclusive as associaçôes entre 'branco-positivo' e 'negro-negativo', semelhantes ao que pudemos observar na fala de uma das professoras no início do artigo. Em decorrência, tendem a desvalorizar o mundo negro, ou mesmo considerá-lo insignificante para suas vidas.

Das várias situaçōes favoráveis à manutenção das distorçōes a respeito de suas matrizes negras, já analisamos brevemente a função da educação formal. Os efeitos psicológicos provocados por esses processos são, como sugerido por Parham \& Helms (1985), que as pessoas tendem a apresentar autoconceito e auto-realização pobres, baixa auto-estima, alta ansiedade e depressão.

\section{A possibilidade de uma identidade afrocentrada}

Os processos descritos vão se modelando e sedimentando a partir das relações pessoais do dia a dia, envolvendo as primeiras experiências com a família de origem, com as pessoas agrupadas ao núcleo familiar, na comunidade e na escola, cobrindo toda fase de infância, adolescência e início da fase adulta. Uma identidade assim constituída tem como uma de suas funções filtrar as experiências, de tal forma que as informações assimiladas são aquelas que se 'encaixam' na estrutura pessoal presente, permitindo à pessoa sentir-se centrada, articulada nas situaçôes de vida e ter um bom grau de controle e previsibilidade sobre elas. Há, entretanto, a possibilidade de experiências 'desconfirmatórias' que, gradualmente, podem provocar transformações, num processo necessariamente conflitivo. Isto se dá quando ocorrem experiências cruciais que questionem sua maneira de ser e de ver o mundo. É o momento no qual torna-se impossível negar a rejeição sofrida socialmente. São experiências com efeito de choque e que destroem a funcionalidade da visão de mundo presente, ao mesmo tempo que sugerem nova direção 
para uma transformação ou ressocialização.

Tomemos como exemplo uma situação comum do nosso dia a dia. Imaginemos duas pessoas negras, funcionárias de determinada empresa, submetidas a situações de discriminação etno-racial. Uma delas pode, diante de tal fato, assumir a atitude de que 'deve aprender a lidar com as pancadas da vida'; a outra pode descrever o efeito da situação como 'aquele que a ensinou a ver ser a discriminação, a que está constantemente submetida, um verdadeiro obstáculo’. No primeiro caso, a pessoa abstrai a variável etno-racial de sua interpretação, tendendo a manter sua estrutura psicológica; no segundo, a situação sugere uma tomada de consciência da discriminação que tem sofrido. É um momento de impacto. À medida que assimila essas novas informações e passa a usá-las como referências pessoais, a pessoa é desafiada a repensar de maneira radical suas concepçóes sobre as questões negras.

As situações de impacto, inicialmente, provocam reações intensas e de muita angústia. Após o período de conflito no qual o afro-descendente vê desarticular-se a estrutura de subjetividade provedora de sustentação e segurança, pode haver o início de um processo de intensa metamorfose pessoal em que, gradualmente, vai demolindo velhas perspectivas, referências de mundo em torno das quais construía sua identidade e, ao mesmo tempo, passa a desenvolver uma nova estrutura pessoal referenciada em valores etno-raciais de matrizes africanas. No início da transformação, entretanto, a pessoa ainda não tem familiaridade com a nova estrutura que pretende desenvolver, com a pessoa em que deseja transformar-se. "O novo convertido tem falta de conhecimento sobre a complexidade e textura da nova identidade e é forçado a construir uma imagem especulativa de self simplista, glorificada e altamente romantizada, que ele acredita ser a correta." (CROss, 1991: 202). É um momento de intensa militância no mundo negro.

É provável que tal situação explique por que é comum o afro-descendente apegar-se de forma obsessiva a símbolos da nova identidade em processo de construção, a jargões verbais, a algumas ideologias rígidas e a avaliações dicotômicas. Envolvido na transformação da identidade e, simultaneamente, na busca das características básicas daquele em que quer tornar-se, o indivíduo passa a julgar os outros afro-descendentes em conformidade com seus padrōes 'idealizados', desenvolvendo uma forma tendenciosa e extremada de atacar pessoas que aparentemente demonstram valores antigos e afirmando os novos valores de uma forma bizarra.

Pelo fato de as concepções da pessoa, nesse período, estarem articuladas com uma visão dicotômica de mundo, existe a tendência de considerar todos os brancos 
como maus, desumanos e inferiores e, os negros, como superiores. Entretanto, gradualmente, a pessoa mergulha no mundo negro, passando a participar de grupos em que seus valores são intensamente afirmados. O grupo apoia o 'convertido', valorizando novos códigos, roupas, comportamentos, favorecendo um padrão de conformidade por parte do novo militante. É possível que as pessoas passem a participar de movimentos e organizações voltadas para a busca de estratégias de combate à discriminação racial, movimentos de valorização da cultura negra e em torno de expressões artísticas relacionadas ao tema. No entanto, ocorre uma situação paradoxal: para fugir ao conformismo de uma fase em que se submetia aos valores brancos, o indivíduo pode incorrer num outro tipo de conformismo - o do novo grupo etno-racial de referência, desenvolvendo uma aversão e negação dos valores brancos, atribuindo a causa dos problemas sofridos anteriormente às pessoas brancas e ao seu mundo branco, portanto não numa perspectiva de afirmação positiva de suas referências negras.

Trata-se de um problema apontado por Figueiredo, num ensaio em que são analisados aspectos da identidade das pessoas que participam da militância como um modo de vida. $\mathrm{O}$ militante tende a desenvolver uma identidade apoiada em procedimentos de exclusão e vedamento que resultam na "repetição estéril do próprio terreno que pretendia transformar" (1995: 114). Tratando-se do desenvolvimento de uma identidade articulada em torno de características etno-raciais, o fechamento em torno de suas novas referências pode provocar a fixação da pessoa nesse estágio, ou seja, alimentar uma atitude preconceituosa, agora contra o euro-descendente, preservando exatamente o mesmo padrão de subjetividade que visava transformar.

Apesar dos riscos, reafirmamos que a militância permite que os aspectos da história e cultura que foram omitidos sejam conhecidos. Gradualmente, o afrodescendente tende a desenvolver um controle sobre sua emocionalidade, com o abandono das ideologias simplificadoras, freqüentemente reconhecendo suas primeiras impressões sobre a negritude como românticas e idealizadas. Há certa decepção com relação aos grupos radicais, que o leva a participar de grupos mais seriamente voltados para uma reversão da discriminação e valorização das matrizes africanas, além de estimular a articulação simultânea com diversos grupos.

Nesse momento, pode ocorrer a internalização de valores de matrizes africanas e a construção de uma identidade positivamente afirmada, pois, aos 
poucos, a pessoa desenvolve uma perspectiva afro-centrada, menos estereotipada, com atitudes mais expansivas, mais abertas e menos defensivas, voltadas para a valorização das qualidades referentes à negritude, em que as matrizes africanas são salientadas. O grupo negro torna-se o principal grupo de referência, sendo seu vínculo determinado por qualidades do próprio grupo e não por uma postura de contraposição ao mundo branco. Torna-se possível também realizar coalizões com membros de outros grupos organizados em torno de projetos ou valores distintos.

Essa 'nova' identidade, já referenciada em matrizes africanas, passa a ter uma função protetora. $\mathrm{O}$ indivíduo tem consciência de que o racismo ainda faz parte da experiência brasileira e de que voltará a ser alvo de atitudes racistas; no entanto, a partir desse momento, terá desenvolvido recursos de defesa, um sistema de censura e uma orientação de eficácia pessoal que o predispõe a atribuir a culpa de circunstâncias adversas a outros fatores e não mais somente a si mesmo. Desenvolve-se, assim, a consciência da importância das matrizes africanas na construção de sua identidade. $\mathrm{O}$ afro-descendente passa a sentir-se aceito, com propósito de vida, e percebe-se profundamente enraizado na cultura negra, sem deixar de notar as condiçōes às quais está submetido num mundo que o vê com preconceito. As matrizes africanas passam a ser efetivamente afirmadas.

\section{Conclusões}

Há preconceito e discriminação étnica no ambiente escolar, e estes já são percebidos desde a pré-escola. Conseqüentemente, a criança negra percebe diferenças quanto à sua aceitação e às formas de tratamento que lhe são conferidas por parte dos adultos à sua volta, bem como pelas crianças brancas. Como aponta E. S. Cavalleiro,

... essa percepção compele a criança negra à vergonha de ser negra. Confere-lhe sua participação em um grupo 'invisível' dentro da escola. Esse procedimento pode minar, aos poucos, a sua identidade. À criança branca resta a compreensão de sua superioridade étnica, irreal, e o entendimento da inferioridade, também irreal, dos indivíduos negros. (1998: 129) 
Assim, a dinâmica entre o indivíduo negro e a sociedade é marcada por episódios de desqualificação pessoal e assimilação de sua 'inferioridade', dificultando de forma perversa seu exercício de cidadania. Uma vez que o indivíduo constitui sua identidade pela experiência de vida articulada em suas representações sociais, construídas a partir da experiência coletiva, instaura-se um complexo processo de múltiplas dimensões, sendo, portanto, de difícil reversão.

A escola, no papel do educador, enquanto espaço para a divulgação e perpetuação de modelos sociais, não pode omitir-se na discussão das relaçôes raciais. Para isso, acreditamos ser um lugar em que o preconceito e a discriminação racial devem ser sistematicamente apontados e abertamente debatidos. A formação dos professores em relação a tais questôes torna-se fundamental para que situações, como as apontadas no início do trabalho, deixem de ocorrer. Parece-nos de suma importância uma reavaliação dos conteúdos que constituem o currículo escolar e uma formação pedagógica com propósitos de inserção social das diferenças, de forma que as relações raciais que afetam o processo de aprendizagem e colaboram para 'construir' indivíduos estigmatizados possam ser melhoradas. A educação formal deve enfatizar as nossas raízes nos currículos, reconstruindo a história da formação do povo brasileiro, não mais sob a óptica branca oficial, mas com uma visão mais abrangente. Além disso, a ação do educador deve estender-se de sua atuação em sala de aula para os órgãos de classe, bem como no trabalho extra-escolar.

Naturalmente, a escola por si só não solucionará todas as questões que solidificaram o árido terreno do preconceito e discriminação raciais, mas poderá tornar-se um indicador de caminhos possíveis para a eqüidade inter-racial, de efetivação e gozo da exaustivamente debatida 'democracia racial', idealizada pela voz de Gilberto Freire.

Dessa forma, o negro, nascido num meio física e socialmente adverso, teria condiçôes de desenvolver forças para a luta, a partir de sua história ancestral, e não pela cor da pele ou por um status que lhe foi atribuído por uma sociedade referenciada em outra cor. Assim, sentir-se-á instalado num grande território, construído sobre uma cosmovisão africana, contendo muitos parceiros e não mais num pequeno lugar nas franjas da sociedade, antes a ele destinado.

O brasileiro negro, vítima de um processo histórico hostil, talvez possa transformar-se, hoje, de sobrevivente em construtor de um novo caminho - o de uma identidade afro-descendente e do sentido de autoria da própria história. 
KEY WORDS: African-descendant brazilian; racial prejudice; discrimination; identity.
ABSTRACT: This article, coming from two daily life paradigmatic situations, points out some specificities on the ways prejudice and racial discrimination are publicized in Brazil; and how these processes are fed and supported; shows how that context creates difficulties to raise identities supported by positive values and, as a result, make it hard to exercise citizenship. Finally, indicates a process to allow the construction of an African oriented identity. The focus stays at the school environment seen as a place where those processes are reinforced.

\section{REFERÊNCIAS BIBLIOGRÁFICAS}

Alvarez, H. F. Fundamentos de un modelo integrativo en psicoterapia. Buenos Aires: Paidós, 1992.

Berger, P. L. \& LuCKMAn, T. The social construction of reality: a treatise in the sociology of knowledge. Harmondsworth: Penguin Books, 1972.

Cavall eiro, E. S. Do silêncio do lar ao silêncio escolar: racismo, preconceito e discriminação na educação infantil. São Paulo, Faculdade de Educação da Universidade de São Paulo,1998. Dissertação de mestrado. 218 p.

Ciampa, A. C. A estória do Severino e a história da Severina: um ensaio de psicologia social. São Paulo: Brasiliense, 1987.

Consorte, J. G. A mestiçagem no Brasil: armadilhas e impasses. Margem, 10: 107-117, 1999.

Cross, W. E., Jr. Shades of black: diversity in African-American identity. Philadelphia: Temple University Press, 1991.

D'adesky, J. Pluralismo étnico e multiculturalismo: racismos e anti-racismos no Brasil. São Paulo, - Departamento de Antropologia Social da Faculdade de Filosofia, Letras e Ciências Humanas da Universidade de São Paulo, 1996. Tese de Doutorado. 340 p.

Fer reir a, R. F. Uma história de lutas e vitórias: a construção da identidade de um 
afrodescendente brasileiro. São Paulo, Instituto de Psicologia da Universidade de São Paulo,1999. Tese de doutorado. 281 p.

Figueir edo, L. C. Modos de subjetivação no Brasil e outros escritos. São Paulo: Educ/Escuta, 1995.

Gusmão, N. M. M. A dimensão política da cultura negra no campo: uma luta, muitas lutas. São Paulo, Faculdade de Filosofia, Letras e Ciências Humanas da Universidade de São Paulo, 1990. Tese de doutorado.

Lima, L. A. N. Capoeira Angola - Lição de vida na civilização brasileira. São Paulo, Faculdade de Psicologia da Pontifícia Universidade Católica de São Paulo,1991. Dissertação de mestrado. $142 \mathrm{p}$.

Merl eau-Ponty, M. O visivel e o invisível. São Paulo: Perspectiva, 1971.

Miranda, M. G. O processo de socialização na escola: a evolução da condição social da criança. In: Lane, S. T. M. \& Codo, W. (orgs.). Psicologia social: o homem em movimento. 8. ed. São Paulo: Brasiliense, 1989. p. 125-135.

Nasciment o, E. L. (org.). A África na escola brasileira. Relatório do $1^{\circ}$ Fórum Estadual sobre o Ensino da História das Civilizações Africanas na Escola Pública. Brasília, Senado Federal, Gabinete do Senador Abdias do Nascimento, 1991. . Sortilégio da Cor. São Paulo, 2000. 485 p. Tese (Doutorado) - Instituto de Psicologia, Universidade de São Paulo.

Parham, T. A. \& Hel ms, J. E. Relation of racial identity attitudes to self-actualization and affective states of black students. Journal of Counseling Psychology,32: 3, p. 431-440, 1985.

Per eir a, J. B. B. Racismo à brasileira. In: Munanga, K. (org.) Estratégias e políticas de combate à discriminação racial. São Paulo: Edusp/Estação Ciência, 1996. p. 75-78.

Pinsky, J. A escravidão no Brasil. 17. ed. rev. e ampl. São Paulo: Contexto, 2000.

Reis, E. A. Mulato: negro-não-negro elou branco-não-branco-Um estudo psicossocial sobre identidade. São Paulo, Faculdade de Psicologia da Pontifícia Universidade Católica de São Paulo,1997. Dissertação de mestrado. 107 p.

Ribeiro, R. I. Alma africana no Brasil. São Paulo: Oduduwa, 1996.

Rodrigues, F. Racismo cordial. In: _. Racismo cordial - Folha de S. Paulo-Datafolha. A mais completa análise sobre o preconceito de cor no Brasil. São Paulo: Ática, 1995. p. 11-55.

Rodrigues, R. N. Os africanos no Brasil (1932). Brasília: Editora da Universidade 
de Brasília, 1988.

Schwarcz, L. M. Usos e abusos da mestiçagem e da raça no Brasil: Uma história das teorias raciais em finais do século XIX. Afro-Ásia, 18, p. 77-101, 1996.

Nem preto nem branco, muito pelo contrário: cor e raça na intimidade. In: Schwarcz, L. K. M. (org.). História da vida privada no Brasil: contrastes da intimidade contemporânea. São Paulo: Companhia das Letras, 1998. v. 4, p. 173-244.

Souza, I. S. O resgate da identidade na travessia do movimento negro: arte, cultura e política. São Paulo, Instituto de Psicologia da Universidade de São Paulo, 1991. Tese de doutorado. 376 p. 